\title{
Effects of low temperature on photosynthetic characteristics in the super-high-yield hybrid rice 'Liangyoupeijiu' at the seedling stage
}

\author{
D.W. Shi ${ }^{1,2}$, X.D. Wei ${ }^{3}$ and G.X. Chen ${ }^{4}$ \\ ${ }^{1}$ Co-Innovation Center for Sustainable Forestry in Southern China, \\ Nanjing Forestry University, Nanjing, Jiangsu, China \\ ${ }^{2}$ College of Biology and the Environment, Nanjing Forestry University, \\ Nanjing, Jiangsu, China \\ ${ }^{3}$ Institute of Food Crops, Jiangsu High Quality Rice R\&D Center, \\ Jiangsu Academy of Agricultural Sciences, Nanjing, Jiangsu, China \\ ${ }^{4}$ College of Life Sciences, Nanjing Normal University, Nanjing, Jiangsu, \\ China \\ Corresponding author: D.W. Shi \\ E-mail: sdw1982@njfu.edu.cn
}

Genet. Mol. Res. 15 (4): gmr15049021

Received July 22, 2016

Accepted October 19, 2016

Published December 2, 2016

DOI http://dx.doi.org/10.4238/gmr15049021

\begin{abstract}
To elucidate the resistance of high-yield hybrid rice (Oryza sativa L.) at the seedling stage to low temperature, photosynthetic characteristics, such as membrane lipid peroxidation, fatty acid composition, and chloroplast ultrastructure, were investigated in a newly developed super-hybrid rice ('Liangyoupeijiu') and a traditional chill-sensitive hybrid rice ('Shanyou63'), with $20^{\circ} \mathrm{C}$ as the control condition and $10^{\circ} \mathrm{C}$ as the low temperature treatment. Chlorophyll content, oxygen consumption by photosystem I, and oxygen production by photosystem II in the thylakoid membrane mainly decreased under the low-temperature treatment. The malondialdehyde content of 'Liangyoupeijiu' decreased slightly, while increases in membrane lipid peroxidation were greater in $10^{\circ} \mathrm{C}$-treated than in $25^{\circ} \mathrm{C}$-treated
\end{abstract}


'Shanyou63' seedlings. The index of unsaturated fatty acids increased in the two cultivars, particularly in 'Liangyoupeijiu'. No severe chloroplast ultrastructure damage was observed under cold stress, but the number of osmiophilic granules in 'Shanyou63' increased rapidly. The results indicate that compared to 'Shanyou63', 'Liangyoupeijiu' is more chill-resistant at the seedling stage.

Key words: Rice (Oryza sativa L.); Low temperature;

Photosynthetic electron transport; Lipid peroxidation; Fatty acid;

Chloroplast ultrastructure

\section{INTRODUCTION}

Rice (Oryza sativa L.), which originated in the subtropics, is strongly affected by low temperature (Gesch and Heilman, 1999). Under chilling stress, seedlings in early spring often have a rotten appearance, and problems during the grain-filling stage are also observed in late autumn (Ji et al., 2003). Therefore, improving the tolerance of rice plants to chilling temperatures would increase rice production (Kakar et al., 2016).

Photosynthesis is often the first process to be inhibited by chilling temperatures (Huo et al., 2016), which can be very harmful to a plant photosynthetic capacity. The photochemical activity of isolated chloroplasts decreases after chilling, and photosystem I (PSI) activity decreases more rapidly than that of photosystem II (PSII) (Yun et al., 1997). Some negative effects of chilling may be because of an increased production of reactive oxygen species (ROS), the accumulation of which may lead to an increase in lipid peroxidation (Adamski et al., 2016). High levels of unsaturated fatty acids in chloroplast thylakoid membranes increase chilling resistance in higher plants (Botella et al., 2016).

'Liangyoupeijiu' is a newly developed two-line super-high-yield rice hybrid ('Pei-ai 64 s' x '9311'). This hybrid has a higher water consumption and longer maturing period than traditional cultivars (Chen et al., 2004). Previous studies have investigated its photosynthetic properties under normal conditions (Zhang et al., 2010), under high temperature (Ou et al., 2005), under different nitrogen rates (Wang et al., 2012), and under enhanced ultraviolet-B radiation (Yu et al., 2013). In the present study, photosynthetic electron transport, lipid peroxidation, unsaturated fatty acid levels, and chloroplast ultrastructure were compared between 'Liangyoupeijiu' and the traditional cultivar 'Shanyou63' under chilling stress at the seedling stage, in order to provide a theoretical basis for the selection of high-yield hybrid rice.

\section{MATERIAL AND METHODS}

\section{Plant materials and treatments}

Seeds of both varieties were obtained from the Institute of Food and Crops, Jiangsu Academy of Agricultural Sciences (Nanjing, Jiangsu, China). The seeds were germinated on Petri dishes on wet filter paper at $30^{\circ} \mathrm{C}$ in the dark. After $48 \mathrm{~h}$ of incubation, uniformly germinated seeds were selected and cultivated in a Kimura B nutrient solution. Seedlings were grown under a $12 \mathrm{~h}$ photoperiod, $25 / 20^{\circ} \mathrm{C}$ day/night air temperatures, and a photosynthetic photon flux density (PPFD) of $1000 \mu \mathrm{mol} \cdot \mathrm{m}^{-2} \cdot \mathrm{s}^{-1}$. Chilling started when the second leaf was

Genetics and Molecular Research 15 (4): gmr15049021 
fully expanded. Half of the seedlings of each cultivar were placed in a separate growth chamber with the same photoperiod, a $25 / 10^{\circ} \mathrm{C}$ day/night temperature, and a PPFD of $1000 \mu \mathrm{mol} \cdot \mathrm{m}^{-}$ ${ }^{2} \cdot \mathrm{s}^{-1}$, while the remaining were maintained under a $25 / 20^{\circ} \mathrm{C}$ day/night temperature regime as controls. Leaf samples were collected every 2 days.

\section{Measurement of chlorophyll content}

The chlorophyll content was measured using the method of Arnon (1949), with 80\% $(\mathrm{v} / \mathrm{v})$ acetone.

\section{Determination of PSI and PSII activity}

The photosynthetic electron transport rates in the thylakoid membranes (PSI and PSII activity) were determined by the method of Coombs et al. (1985) using an oxygen electrode (Oxy-Lab Type, Hansatech, Norfolk, UK). Rates are expressed as $\mu \mathrm{mol} \mathrm{O}_{2} \cdot \mathrm{g} \mathrm{chl}^{-1} \cdot \mathrm{min}^{-1}$.

\section{Preparation of thylakoid membranes}

The thylakoid membranes were isolated from the rice leaves at $4^{\circ} \mathrm{C}$ according to the method of Dunahay et al. (1984), with minor modifications. The rice leaves were irradiated before thylakoid isolation. Light-treated leaves $(1 \mathrm{~g})$ were homogenized in chilled grinding buffer $\mathrm{B}_{1}\left[0.4 \mathrm{M}\right.$ sucrose, $2 \mathrm{mM} \mathrm{MgCl}_{2}, 0.1 \%$ bovine serum albumin (BSA), and $20 \mathrm{mM}$ tricine, $\mathrm{pH}$ 8.0]. The homogenate was filtered through four layers of cheesecloth, and the filtrate was centrifuged at $3000 \mathrm{~g}$ for $2 \mathrm{~min}$; the supernatant was then centrifuged at $4000 \mathrm{~g}$ for $10 \mathrm{~min}$. The chloroplast pellet was resuspended in buffer $\mathrm{B}_{2}(0.15 \mathrm{M}$ sucrose, $5 \mathrm{mM} \mathrm{MgCl}$, $0.2 \% \mathrm{BSA}$, and $20 \mathrm{mM}$ tricine, $\mathrm{pH} 8.0$ ) with a glass homogenizer, and the thylakoids were pelleted at $4000 \mathrm{~g}$ for $10 \mathrm{~min}$. The thylakoid membranes collected were resuspended in buffer $\mathrm{B}_{3}$ [15 $\mathrm{mM} \mathrm{NaCl}, 5 \mathrm{mM} \mathrm{MgCl}$, and $20 \mathrm{mM}$ 2-(N-morpholino) ethanesulfonic acid, $\mathrm{pH}$ 6.5] to a concentration of $2 \mathrm{mg} / \mathrm{mL}$ chlorophyll.

\section{Analysis of fatty acids}

Lipids were extracted from the thylakoid membranes with a mixture of chloroform and methanol $(1: 2 ; \mathrm{v} / \mathrm{v})$, and fatty acids were analyzed by the procedure described by Diao et al. (1997). Extracted lipids were subjected to methanolysis in the presence of a mixture of $\mathrm{H}_{2} \mathrm{SO}_{4}$ and methanol $(5: 95 ; \mathrm{v} / \mathrm{v})$, using heptadecanoic acid $\left(\mathrm{C}_{17: 0}\right)$ as an internal standard at $85^{\circ} \mathrm{C}$ for 60 min. Fatty acid analysis was performed using a Hewlett-Packard 5890 Gas Chromatograph (Hewlett-Packard Company, Wilmington, DE, USA) equipped with a hydrogen flameionization detector with a 33-m capillary column. The fatty acids were identified based on their retention times in comparison with those of known standards.

\section{Determination of lipid peroxidation}

Lipid peroxidation was determined based on the malondialdehyde (MDA) content, according to the method of Zhao and $\mathrm{Li}$ (1999). Leaf discs (100 mg) were homogenized in 5 $\mathrm{mL} 0.05 \mathrm{M}$ phosphate buffer, $\mathrm{pH} 7.8$, at $4^{\circ} \mathrm{C}$, and the homogenate was centrifuged at 12,000

Genetics and Molecular Research 15 (4): gmr15049021 
$g$ for $20 \mathrm{~min}$. A $1.5 \mathrm{-mL}$ aliquot of the supernatant was mixed with $2.5 \mathrm{~mL} 20 \%$ trichloroacetic acid and $0.5 \%$ thiobarbituric acid. After placing in boiling water for $10 \mathrm{~min}$ and cooling quickly, the mixture was centrifuged at $2000 \mathrm{~g}$ for $15 \mathrm{~min}$. The absorbance of the supernatant was measured at 532, 600, and $450 \mathrm{~nm}$ with a UV-Vis spectrophotometer UV-2550 (Shimadzu Corporation, Kyoto, Japan). The MDA content was calculated using the following equation: $\mathrm{C}$ $(\mu \mathrm{M})=6.45\left(\mathrm{~A}_{532}-\mathrm{A}_{600}\right)-0.56 \mathrm{~A}_{450}$.

\section{Electron microscopy}

The leaf samples were cut into small pieces and fixed in $4 \%(\mathrm{v} / \mathrm{v})$ glutaraldehyde dissolved in $0.3 \mathrm{M}$ sodium phosphate buffer, $\mathrm{pH} 7.5$, for $2 \mathrm{~h}$. The samples were post-fixed with $1.0 \% \mathrm{OsO}_{4}$ in the same buffer, and after $2 \mathrm{~h}$, the samples were dehydrated in graded acetone solutions and embedded in an epoxy resin mixture. Ultra-thin sections $(70 \mathrm{~nm})$ were obtained using a LKB-V ultramicrotome, stained with uranyl acetate followed by lead citrate, and observed in a Hitachi H-600A-2 transmission electron microscope (Hitachi, Tokyo, Japan).

\section{RESULTS}

\section{Membrane lipid peroxidation}

The effects of low temperature on leaf MDA content are shown in Figure 1. Under chilling conditions, a lower level of lipid peroxidation was observed in 'Liangyoupeijiu' than in the control seedlings, while low temperature caused a distinct increase in the MDA concentration in 'Shanyou63'.

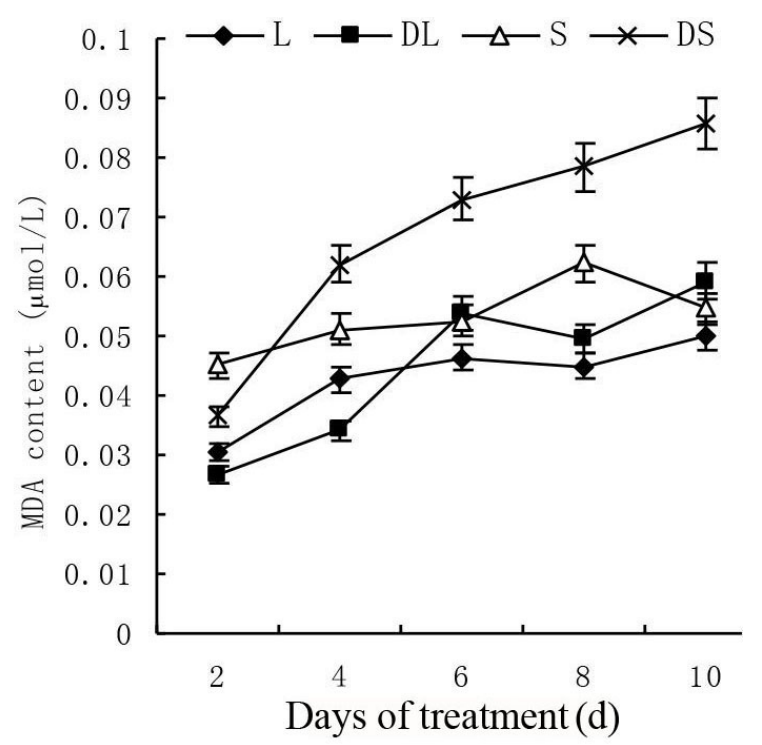

Figure 1. Effects of low temperature on the malondialdehyde (MDA) content of 'Liangyoupeijiu' and 'Shanyou63' seedlings. Data points represent the means \pm SEM of three independent measurements. $L=$ 'Liangyoupeijiu' under control temperature $\left(25^{\circ} \mathrm{C}\right)$; $\mathrm{DL}=$ 'Liangyoupeijiu' under low temperature $\left(10^{\circ} \mathrm{C}\right) ; \mathrm{S}=$ 'Shanyou63' under control temperature $\left(25^{\circ} \mathrm{C}\right)$; DS $=$ 'Shanyou63' under low temperature $\left(10^{\circ} \mathrm{C}\right)$.

Genetics and Molecular Research 15 (4): gmr15049021 


\section{Chlorophyll content and photosynthetic electron transport}

Figure 2 shows the changes in chlorophyll content after treatment. Under the chilling temperature, the chlorophyll content significantly decreased compared to that in the control. On the 10th day of chilling, the chlorophyll content had decreased by 75 and $82 \%$ in 'Liangyoupeijiu' and 'Shanyou63', respectively. 'Shanyou63' had a higher chlorophyll concentration than 'Liangyoupeijiu' throughout the experiment.

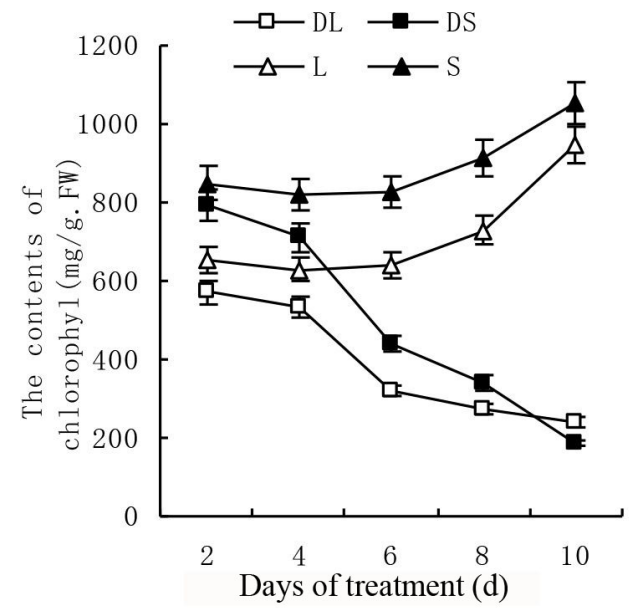

Figure 2. Effects of low temperature on the chlorophyll content of 'Liangyoupeijiu' and 'Shanyou63' seedlings. Data points represent the means \pm SEM of three independent measurements. $\mathrm{L}=$ 'Liangyoupeijiu' under control temperature $\left(25^{\circ} \mathrm{C}\right) ; \mathrm{DL}=$ 'Liangyoupeijiu' under low temperature $\left(10^{\circ} \mathrm{C}\right) ; \mathrm{S}=$ 'Shanyou63' under control temperature $\left(25^{\circ} \mathrm{C}\right)$; DS $=$ 'Shanyou63' under low temperature $\left(10^{\circ} \mathrm{C}\right)$.

The photosynthetic electron transport rates in the leaves of the two cultivars had decreased compared to that in the control. Electron flow rates through PSI decreased by 83 and $77 \%$ in 'Liangyoupeijiu' and 'Shanyou63', respectively, by the 10th day of treatment (Table 1), and oxygen production by PSII had decreased by 85 and $91 \%$ in 'Liangyoupeijiu' and 'Shanyou63', respectively, by the 10th day of treatment (Table 2).

Table 1. Effects of low temperature on oxygen consumption by photosystem I (PSI) in the thylakoid membranes of rice seedlings.

\begin{tabular}{l|c|c|c|c}
\hline \multirow{2}{*}{ Days of treatment } & \multicolumn{4}{|c}{ Oxygen consumption of PSI $\left(\mu \mathrm{mol} \mathrm{O}_{2} \cdot \mathrm{g} \mathrm{chl}^{-1} \cdot \mathrm{min}^{-1}\right)$} \\
\cline { 2 - 5 } & $\mathrm{L}$ & $\mathrm{DL}$ & $\mathrm{S}$ & $\mathrm{DS}$ \\
\hline 2 & $653.27 \pm 32.65$ & $459.76 \pm 19.05$ & $570.58 \pm 28.54$ & $515.23 \pm 24.76$ \\
\hline 4 & $720.14 \pm 34.27$ & $423.61 \pm 21.30$ & $600.13 \pm 27.06$ & $509.68 \pm 26.14$ \\
\hline 6 & $874.41 \pm 38.07$ & $377.08 \pm 20.69$ & $680.29 \pm 32.64$ & $490.34 \pm 21.08$ \\
\hline 10 & $1040.21 \pm 52.26$ & $303.57 \pm 15.17$ & $760.29 \pm 41.64$ & $423.06 \pm 24.78$ \\
\hline
\end{tabular}

$\mathrm{L}=$ 'Liangyoupeijiu' under control temperature $\left(25^{\circ} \mathrm{C}\right) ; \mathrm{DL}=$ 'Liangyoupeijiu' under low temperature $\left(10^{\circ} \mathrm{C}\right) ; \mathrm{S}$ $=$ 'Shanyou63' under control temperature $\left(25^{\circ} \mathrm{C}\right)$; DS $=$ 'Shanyou63' under low temperature $\left(10^{\circ} \mathrm{C}\right)$. Each value represents the average of three measurements \pm SEM.

Genetics and Molecular Research 15 (4): gmr15049021 
Table 2. Effects of low temperature on oxygen production by photosystem II (PSII) in the thylakoid membranes of rice seedlings.

\begin{tabular}{l|c|c|c|c}
\hline \multirow{2}{*}{ Days of treatment } & \multicolumn{4}{|c}{ Oxygen production of PSII $\left(\mu \mathrm{mol} \mathrm{O}_{2} \cdot \mathrm{g} \mathrm{chl}^{-1} \cdot \mathrm{min}^{-1}\right)$} \\
\cline { 2 - 5 } & $\mathrm{L}$ & $\mathrm{DL}$ & $\mathrm{S}$ & $177.09 \pm 8.95$ \\
\hline 2 & $196.05 \pm 11.08$ & $147.25 \pm 7.69$ & $186.27 \pm 9.26$ & $165.04 \pm 8.26$ \\
\hline 4 & $236.15 \pm 12.34$ & $140.31 \pm 6.59$ & $215.04 \pm 12.36$ & $160.23 \pm 9.05$ \\
\hline 6 & $261.47 \pm 12.68$ & $125.06 \pm 5.32$ & $222.05 \pm 13.48$ & $144.06 \pm 6.75$ \\
\hline 8 & $274.31 \pm 15.48$ & $95.47 \pm 5.07$ & $234.58 \pm 10.26$ & $118.21 \pm 5.68$ \\
\hline 10 & $284.31 \pm 14.36$ & $42.13 \pm 2.35$ & $21.58 \pm 1.24$ \\
\hline
\end{tabular}

$\mathrm{L}=$ 'Liangyoupeijiu' under control temperature $\left(25^{\circ} \mathrm{C}\right) ; \mathrm{DL}=$ 'Liangyoupeijiu' under low temperature $\left(10^{\circ} \mathrm{C}\right) ; \mathrm{S}$ $=$ 'Shanyou63' under control temperature $\left(25^{\circ} \mathrm{C}\right)$; $\mathrm{DS}=$ 'Shanyou63' under low temperature $\left(10^{\circ} \mathrm{C}\right)$. Each value represents the average of three measurements \pm SEM.

\section{Fatty acid composition of thylakoid membranes}

Five fatty acids were quantified: palmitic (16:0), stearic (18:0), oleic (18:1), linoleic $(18: 2)$, and linolenic $(18: 3)$. Changes in fatty acid percentages after treatment are shown in Figure 3. Palmitic acid (16:0) accounted for the majority of the saturated fatty acids, and linolenic acid (18:3) accounted for most of the unsaturated fatty acids. Under the chilling temperature, saturated fatty acid levels decreased and unsaturated fatty acid levels increased. For example, in 'Liangyoupeijiu' and 'Shanyou63', levels of palmitic acid (16:0) decreased by 23.0 and $37.0 \%$, respectively, and linolenic acid (18:3) levels increased by 18.4 and $7.5 \%$, respectively. The index of unsaturated fatty acids (IUFA) increased by 21.3 and $12.1 \%$, respectively, in 'Liangyoupeijiu' and 'Shanyou63' (Table 3).

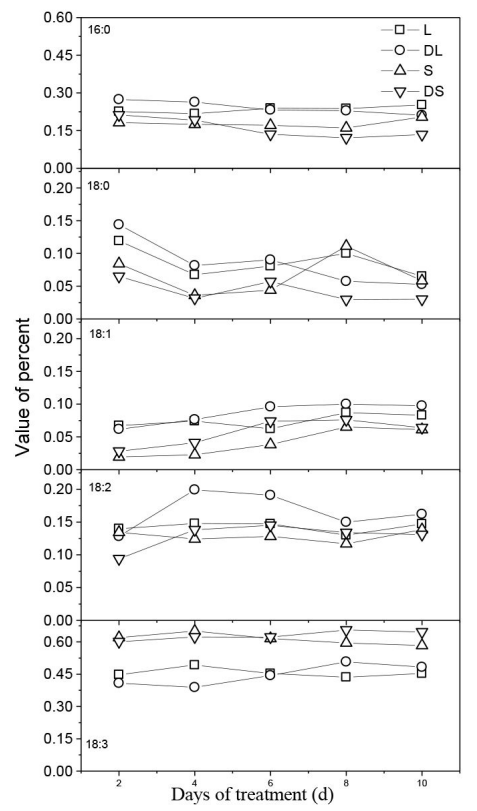

Figure 3. Changes in fatty acid composition of thylakoid membrane lipids in 'Liangyoupeijiu' and 'Shanyou63' seedlings under cold stress $(\mathrm{N}=3) . \mathrm{L}=$ 'Liangyoupeijiu' under control temperature $\left(25^{\circ} \mathrm{C}\right)$; $\mathrm{DL}=$ 'Liangyoupeijiu' under low temperature $\left(10^{\circ} \mathrm{C}\right) ; \mathrm{S}=$ 'Shanyou63' under control temperature $\left(25^{\circ} \mathrm{C}\right)$; DS = 'Shanyou63' under low temperature $\left(10^{\circ} \mathrm{C}\right) .16: 0$, palmitic acid; $18: 0$, stearic acid; 18:1, oleic acid; 18:2, linoleic acid; 18:3, linolenic acid. 
Table 3. Changes in the index of unsaturated fatty acids (IUFA) of thylakoid membrane lipids in 'Liangyoupeijiu' and 'Shanyou63' under chilling.

\begin{tabular}{l|c|c|c|c|c|c}
\hline \multirow{2}{*}{ Cultivar } & Treatment temperature & \multicolumn{4}{|c}{ IUFA } \\
\cline { 2 - 6 } & & 2 days & 4 days & 6 days & 8 days & 10 days \\
\cline { 2 - 7 } & & 169.13 & 184.86 & 172.92 & 165.72 & 173.65 \\
\cline { 2 - 7 } & $25^{\circ} \mathrm{C}$ & 154.26 & 164.10 & 181.04 & 192.19 & 187.06 \\
\hline \multirow{2}{*}{ 'Shangyoupeijiu' } & $10^{\circ} \mathrm{C}$ & 209.19 & 222.11 & 214.26 & 208.43 & 208.73 \\
\cline { 2 - 7 } & $25^{\circ} \mathrm{C}$ & 201.88 & 218.66 & 223.08 & 230.90 & 226.40 \\
\hline
\end{tabular}

IUFA $=(18: 1 \mathrm{~mol} \%+18: 2 \mathrm{~mol} \% \times 2+18: 3 \mathrm{~mol} \% \times 3) \times 100$. The means of three independent measurements are presented.

\section{Chloroplast ultrastructure}

The chloroplasts in the control leaves exhibited a typical chloroplast structure with an elliptical or navicular shape, and thylakoid membranes organized in the granal and stromal membranes (Figure 4). A small number of osmiophilic granules were observed in some chloroplasts. Under the chilling temperature, the chloroplasts of both cultivars were damaged by the 10th day of treatment; they became rounded instead of an elliptical or navicular shape, the thylakoids were swollen, and the intrathylakoid space had increased. However, the number of grana did not significantly change as compared to that in the control plants. Low temperature caused a larger increase in the number of osmiophilic granules in 'Shanyou63' than in 'Liangyoupeijiu'.

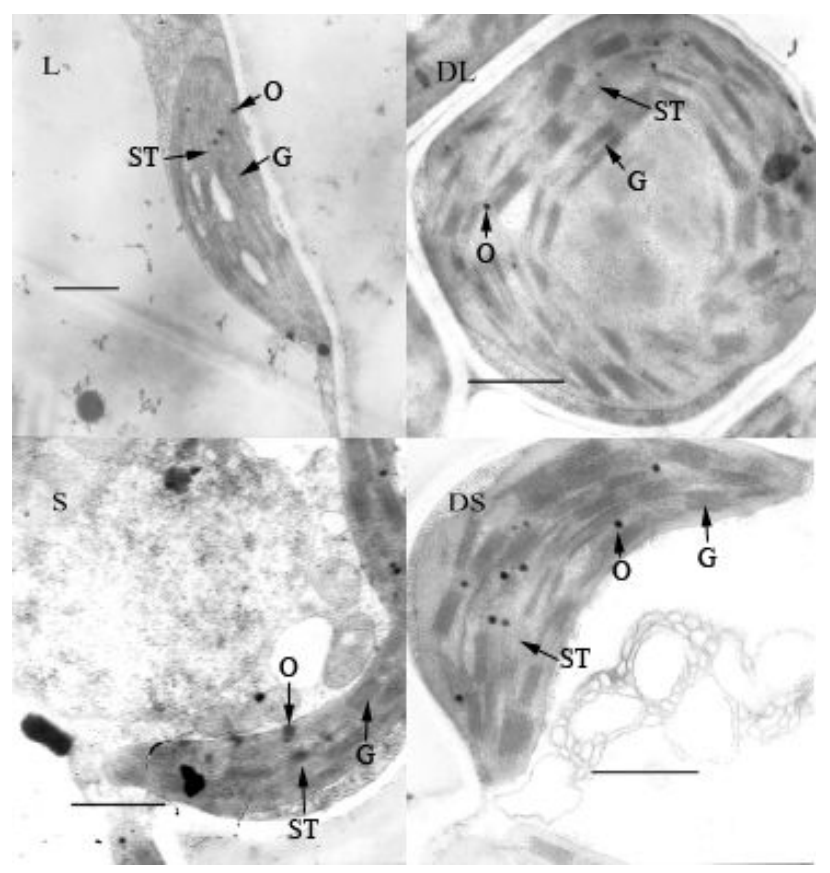

Figure 4. Effects of 10 days of low temperature on chloroplast ultrastructure in 'Liangyoupeijiu' and 'Shanyou63' seedlings. Bar $=1 \mu \mathrm{m} . \mathrm{L}=$ 'Liangyoupeijiu' under control temperature $\left(25^{\circ} \mathrm{C}\right) ; \mathrm{DL}=$ 'Liangyoupeijiu' under low temperature $\left(10^{\circ} \mathrm{C}\right) ; \mathrm{S}=$ 'Shanyou63' under control temperature $\left(25^{\circ} \mathrm{C}\right)$; $\mathrm{DS}=$ 'Shanyou63' under low temperature $\left(10^{\circ} \mathrm{C}\right)$. G, granum thylakoid; ST, stroma thylakoid; O, osmiophilic granule. 


\section{DISCUSSION}

Visual symptoms of chilling damage include a waterlogged appearance, yellowing, wilting, inhibition of plant growth, and acceleration of senescence (Salveit and Morris, 1990). In the present study, chlorophyll content was used to evaluate chilling injury to leaves, the changes in which were related to photosynthetic capacity. The chlorophyll content of the two species was equally reduced by exposure to a chilling temperature. The chlorophyll content was more reduced in 'Shanyou63' than in 'Liangyoupeijiu', indicating that the 'Shanyou63' seedlings had more chilling damage than did the 'Liangyoupeijiu' seedlings. The immediate effect of chilling is injury from photooxidation and reduced photosynthetic efficiency (Hou et al., 2016). Although photosynthetic rates were not directly measured in this study, photosynthetic electron transport rates can indirectly indicate photosynthetic activity. Photosynthetic electron transport is related to photophosphorylation, and increases in the electron transport rate could increase the production of adenosine triphosphate (ATP) and nicotinamide adenine dinucleotide phosphate (NADPH). If the NADPH and ATP supplies from the thylakoid electron transport chain were less than the demand for metabolites by carbon metabolism, there would be a serious risk of metabolism depleting the chloroplast and cytosolic ATP and NADPH pools (Foyer et al., 2002). We found that thylakoid membrane electron transport activity (both PSI and PSII) substantially decreased under a chilling temperature. PSII was more affected by cold stress than was PSI. Changes in photosynthetic electron transport were more evident in 'Shanyou63' than in 'Liangyoupeijiu', suggesting that the 'Shanyou63' seedlings were more damaged by low temperature than were the 'Liangyoupeijiu' seedlings.

Under optimal environmental conditions, electron transport during photosynthesis can lead to ROS production, which, consequently, causes photooxidative damage to chloroplasts, carotenoids, and proteins. ROS are chemically aggressive, and attack the polyunsaturated fatty acid components of membrane lipids, resulting in lipid peroxidation (Shah et al., 2001). This process results in the disruption of the physical and functional properties of membranes (Hussain et al., 2016). In the present study, 'Liangyoupeijiu' had lower levels of lipid peroxidation than the control plants at low temperature, while cold stress resulted in higher lipid peroxidation levels in 'Shanyou63'. This indicates that chilling caused more damage to cell membranes in 'Shanyou63' than in 'Liangyoupeijiu'.

The negative effect of cold treatment on photosynthetic capacity and chlorophyll content may be because of changes in the lipid and protein components of the thylakoid membrane (Mostowska, 1997). The level of unsaturated fatty acids is one of most important factors that determine the physical features of membrane lipids; therefore, changes in unsaturated thylakoid membrane lipid levels could affect the function of integrated proteins, photochemical reactions, and electron transport in the thylakoid membrane (Ivanov et al., 2012). In both cultivars, chilling caused an increase in the unsaturated fatty acid content, a decrease in the saturated fatty acid content, and an elevated ratio of unsaturated:saturated fatty acids in the leaves, implying an increased fluidity of the thylakoid membrane that would affect cell compartmentation (Novitskaya et al., 2000). Compared with the control plants, the IUFA in 'Liangyoupeijiu' changed more rapidly than in 'Shanyou63'. Changes in the lipid composition of chloroplasts are responsible for altered thylakoid membrane structures, which in turn affects photosynthetic activity (Scotti-Campos et al., 2014). With increasing cold stress, some damage to the thylakoid structure was found in both cultivars, but not serious damage. This may have been because of an increase in the IUFA, and the cold acclimation of rice at the early stages

Genetics and Molecular Research 15 (4): gmr15049021 
of chilling treatment (Kuk et al., 2003). The 'Shanyou63' chloroplasts had more osmiophilic granules than did the 'Liangyoupeijiu' chloroplasts; an increase in the number and size of osmiophilic granules is generally attributable to gradual thylakoid membrane degradation (Papdakis et al., 2004). This indicates that the chloroplast ultrastructure in 'Shanyou63' was more damaged than that in 'Liangyoupeijiu' under cold stress.

In summary, chilling led to a decrease in membrane lipid peroxidation in 'Liangyoupeijiu' seedlings, whereas it increased in 'Shanyou63' seedlings. Increases in levels of unsaturated fatty acids could maintain membrane fluidity during exposure to low temperatures, which would cause no serious damage to chloroplast architecture after acclimation. Photosynthetic electron transport rates rapidly decreased under cold stress. Our results indicate that 'Liangyoupeijiu' seedlings are more resistant to chilling than are 'Shanyou63' seedlings, which may be the reason for 'Liangyoupeijiu's higher productivity than traditional rice.

\section{Conflicts of interest}

The authors declare no conflict of interest.

\section{ACKNOWLEDGMENTS}

Research supported by the National Natural Science Foundation (\#31300572), the Priority Academic Program Development of Jiangsu High Education Institutions (PAPD), and the Natural Science Foundation of Jiangsu Province (\#BK20130708).

\section{REFERENCES}

Adamski JM, Cargnelutti D, Sperotto RA, Terra TF, et al. (2016). Identification and physiological characterization of two sister lines of indica rice (Oryza sativa L.) with contrasting levels of cold tolerance. Can. J. Plant Sci. 96: 197-214. http://dx.doi.org/10.1139/cjps-2015-0067

Arnon DI (1949). Copper enzymes in isolated chloroplast. Polyphenol oxidase in Beta vulgaris. Plant Physiol. 24: 1-15. http://dx.doi.org/10.1104/pp.24.1.1

Botella C, Sautron E, Boudiere L, Michaud M, et al. (2016). ALA10, a phospholipid flippase, controls FAD2/FAD3 desaturation of phosphatidylcholine in the ER and affects chloroplast lipid composition in Arabidopsis thaliana. Plant Physiol. 170: 1300-1314.

Chen GX, Liu SH, Zhang CJ and Lu CG (2004). Effects of drought on photosynthetic characteristics of flag leaves of a newly-developed super-high-yield rice hybrid. Photosynthetica 42: 573-578. http://dx.doi.org/10.1007/S11099-005$\underline{0015-0}$

Coombs J, Hall DO, Long SP and Scurlock JMO (1985). Techniques in bioproductivity and photosynthesis. Pergamon Press, New York.

Diao FQ, Zhang WH and Liu YL (1997). Changes in composition and function of thylakoid membrane isolated from barley seedling leaves under salt stress. Acta Phytophysiol. Sin. 23: 105-110.

Dunahay TG, Staehelin LA, Seibert M, Ogilvie PD, et al. (1984). Structural, biochemical and biophysical characterization of four oxygen evolving photosystem II preparations from spinach. Biochim. Biophys. Acta 764: 179-193. http:// dx.doi.org/10.1016/0005-2728(84)90027-6

Foyer CH, Vanacker H, Gomez LD and Harbinson J (2002). Regulation of photosynthesis and antioxidant metabolism in maize leaves at optimal and chilling temperatures. Plant Physiol. Biochem. 40: 659-668. http://dx.doi.org/10.1016/ $\underline{\text { S0981-9428(02)01425-0 }}$

Gesch RW and Heilman JL (1999). Responses of photosynthesis and phosphorylation of the light-harvesting complex of photosystem II to chilling temperature in ecologically divergent cultivars of rice. Environ. Exp. Bot. 41: 257-266. http://dx.doi.org/10.1016/S0098-8472(99)00008-8

Genetics and Molecular Research 15 (4): gmr15049021 
Hou W, Sun AH, Chen HL, Yang FS, et al. (2016). Effects of chilling and high temperatures on photosynthesis and chlorophyll fluorescence in leaves of watermelon seedlings. Biol. Plant. 60: 148-154. http://dx.doi.org/10.1007/ s10535-015-0575-1

Huo C, Zhang B, Wang H, Wang F, et al. (2016). Comparative study of early cold-regulated proteins by two-dimensional difference gel electrophoresis reveals a key role for phospholipase D1 in mediating cold acclimation signaling pathway in rice. Mol. Cell. Proteomics 15: 1397-1411.http://dx.doi.org/10.1074/mcp.M115.049759

Hussain S, Khan F, Hussain HA and Nie L (2016). Physiological and biochemical mechanisms of seed priming-induced chilling tolerance in rice cultivars. Front. Plant Sci. 7: 116. http://dx.doi.org/10.3389/fpls.2016.00116

Ivanov AG, Allakhverdiev SI, Huner NPA and Murata N (2012). Genetic decrease in fatty acid unsaturation of phosphatidylglycerol increased photoinhibition of photosystem I at low temperature in tobacco leaves. Biochim. Biophys. Acta 1817: 1374-1379. http://dx.doi.org/10.1016/j.bbabio.2012.03.010

Ji BH, Cao YY, Xie HS, Zhu SQ, et al. (2003). Changes in violaxanthin deepoxidase activity and unsaturation of thylakoid membrane lipids in Indica and Japonica rice under chilling condition and strong light. Acta Bot. Sin. 45: 1063-1070.

Kakar KU, Ren XL, Nawaz Z, Cui ZQ, et al. (2016). A consortium of rhizobacterial strains and biochemical growth elicitors improve cold and drought stress tolerance in rice (Oryza sativa L.). Plant Biol (Stuttg) 18: 471-483. http:// dx.doi.org/10.1111/plb.12427

Kuk YI, Shin JS, Burgos NR, Hwang TE, et al. (2003). Antioxidative enzymes offer protection from chilling damage in rice plants. Crop Sci. 43: 2109-2117. http://dx.doi.org/10.2135/cropsci2003.2109

Mostowska A (1997). Environmental factors affecting chloroplasts. In: Handbook of photosynthesis (Pessarakli M, ed.). Marcel Dekker, New York.

Novitskaya GV, Suvorova TA and Trunova TI (2000). Lipid composition of tomato leaves as related to plant cold tolerance. Russ. J. Plant Physiol. 47: 728-733. http://dx.doi.org/10.1023/A:1026646826048

Ou ZY, Lin GZ and Peng CL (2005). Response of flag leaves of super high yielding rice Pei'ai 64S/E32 and Liangyoupeijiu to high temperature. Chin. J. Rice Sci 19: 249-254.

Papdakis IE, Dmassi KN, Bosabalidis AM, Therios IN, et al. (2004). Boron toxicity in 'Clementine' mandarin plants grafted on two rootstocks. Plant Sci. 166: 539-547. http://dx.doi.org/10.1016/j.plantsci.2003.10.027

Salveit ME and Morris LL (1990). Overview on chilling injury of horticultural crops. In: Chilling injury of horticultural crops (Wang CY, ed.). CRC Press, Boca Raton.

Scotti-Campos P, Pais IP, Partelli FL, Batista-Santos P, et al. (2014). Phospholipids profile in chloroplasts of Coffea spp. genotypes differing in cold acclimation ability. J. Plant Physiol. 171: 243-249. http://dx.doi.org/10.1016/j. jplph.2013.07.007

Shah K, Kumar RG, Verma S and Dubey SS (2001). Effect of cadmium on lipid peroxidation superoxide anion generation and activities of antioxidant enzymes in growing rice seedlings. Plant Sci. 161: 1135-1144. http://dx.doi.org/10.1016/ $\underline{\mathrm{S} 0168-9452(01) 00517-9}$

Wang Q, Huang JL, He F, Cui KH, et al. (2012). Head rice yield of "super" hybrid rice Liangyoupeijiu grown under different nitrogen rates. Field Crops Res. 134: 71-79. http://dx.doi.org/10.1016/j.fcr.2012.05.001

Yu GH, Li W, Yuan ZY, Cui HY, et al. (2013). The effects of enhanced UV-B radiation on photosynthetic and biochemical activities in super-high-yield hybrid rice Liangyoupeijiu at the reproductive stage. Photosynthetica 51: 33-44. http:// dx.doi.org/10.1007/s11099-012-0081-z

Yun J, Hayashi T, Yazawa S, Yasuda Y, et al. (1997). Degradation of photosynthetic activity of Saintpaulia leaf by sudden temperature drop. Plant Sci. 127: 25-38. http://dx.doi.org/10.1016/S0168-9452(97)00112-X

Zhang MP, Zhang CJ, Yu GH, Jiang YZ, et al. (2010). Changes in chloroplast ultrastructure, fatty acid components of thylakoid membrane and chlorophyll a fluorescence transient in flag leaves of a super-high-yield hybrid rice and its parents during the reproductive stage. J. Plant Physiol. 167: 277-285.http://dx.doi.org/10.1016/j.jplph.2009.09.017

Zhao SM and Li DQ (1999). The modern experimental directory on plant physiology. Science Press, Beijing.

Genetics and Molecular Research 15 (4): gmr15049021 